10 Salinger, M. J., and Gunn, J. M., Nature, 256, 396 (1975).

11 Trouger, M. J., and Gunn, J. M., Nature, 256, $396(1975)$.

12 Libby, L. M., J. geophys. Res., 77, $4310(1973)$

13 Freyer, H. D., and Wiesberg, L., Nature, 252,757 (1974).

14 Williams, J., and Van Loon, H., Australian Conf. Climate and Climatic Change (Melbourne, 1975).

15 Lamb, H. H., Nature, 244, 395 (1973).

16 Keeling, C. D., Geochim. cosmochim. Acta, 24, 299 (1961).

\section{Spontaneous measurement by young children}

WHETHER or not the young child can make transitive inferences $(A>B, B>C \therefore A>C)$ is still a controversial issue. Bryant and Trabasso' have claimed that he can, provided that he remembers the necessary information, but this claim has been disputed ${ }^{2,3}$. Youniss and Furth's main argument is that it is one thing to show that a child can make inferences, but quite another to demonstrate that he puts these inferences to any effect. They cite the measurement experiment of Piaget et al. ${ }^{4}$ as evidence that the child does not make inferences spontaneously to solve problems. Here children had been shown a tower of bricks on a table and asked to build one as big on the floor. A stick the same height as the first tower was available: the question was whether the child would use this as a measure to equate the towers, thus making an inference $(A=B, B=C \therefore A=C)$. Children below 8 -yr old did not measure with the stick, and it was concluded that they had no idea of measurement. We here report experiments which lead to the opposite conclusion.

An alternative interpretation to Piaget's is that children do understand that it is possible to use intervening measures, but did not in this case realise that a direct comparison of the two towers by eye might be unreliable and thus that some measurement was needed. We decided to test this notion in three experiments in which, as the two quantities to be compared were invisible, it was very obvious that a direct comparison was not viable. We predicted that here children would measure.

Our experimental test involved 4 trials; in each the child was given two identical looking black wooden blocks ( 8 inch high, 3 inch wide) side by side on a table. Each had a hole in the top, the complete depth of which could not be seen: the hole was either 6 or 4 inch. In 2 of the 4 trials the holes were the same ( 6 inch with 6 inch, 4 inch with 4 inch): in the other two one hole was 6 inch, the other 4 inch.

Between the two blocks lay a 10-inch long stick: its central 2-inch portion was yellow while the surrounding 4 inch at either end was red, so that the yellow portion was uncovered when placed in a 4 -inch hole and covered in a 6-inch hole.

In each trial the child was asked to find out whether the two holes were the same and, if not, which was the deeper. We wanted to know if the child would spontaneously use the stick as a measure to make this comparison. If he did not on any trial he was given a prompt to use the stick as a measure.

In experiment 1, 20 5-yr olds and 20 6-yr olds were also told on each trial to use the stick though they were not told how. In experiment 2 the same number of 5 and 6-yr olds were told nothing about the stick. In experiment 3 the same number of 5 and 6-yr olds were given the same task as in experiment 2, except that the entrance to the two holes was widened and painted white, to see if this would distract the child from measuring. (The depth of the holes was still invisible.)

Also in each experiment each child was given a pre- and post-test version of Piaget et al.'s measurement task, which was exactly the same except that it was miniaturised, with a toy table and towers and sticks which were either 6 or 4 inch.

All the children failed both traditional tower measuring tests in all three experiments. Many of them were, however, successful in our hole measuring task. As Table 1 shows, the majority of children used the stick as a measure without any prompting, and most of their judgments were correct. A substantial number of children were never prompted and were correct on every trial. There were no significant differences between age groups or experiments. We conclude that young children do have an idea of measuring.

In experiment 4 we tested our idea that a crucial factor is whether or not a child realises that a direct comparison will be unreliable with 405 -yr olds and 40 6-yr olds. Half had to compare holes in Perspex boxes. To make direct comparisons of the visible holes unlikely we changed the depth of the holes in this experiment to 6 and 5.5 inch and we placed the blocks on different tables in both conditions. Otherwise the procedure was the same as before.

The prediction was that Perspex boxes, by encouraging direct comparisons, would lead to less measurement. Although the results (Table 1) provide some partial support for this prediction, the difference was not significant. Many children still measured even in this experiment.

Whatever is the importance of the child's appreciation of the precariousness of direct comparisons, we have established contrary to all preceding evidence that young children can spontaneously use intervening measures. This result has some educational significance and since the measuring must have involved inferences it is strong support for the claim that young children make, and benefit from making, transitive inferences.

\section{P. E. Bryant \\ H. KOPYTYNSKA}

Department of Experimental Psychology,

University of Oxford,

South Parks Road, Oxford, UK

Received January 29; accepted March 10, 1976.

1 Bryant, P. E., and Trabasso, T., Nature, 232,456-458 (1971)

de Boysson Bardies, B., and O'Regan, K., Nature, 246, 531 -534 (1973).

Youniss, O and Furth, H. G., Nature, 244, 314-315(1973)

Pianetry (Routledge and Kegan Paul, London, 1960).

Table 1 Performance in the four experiments

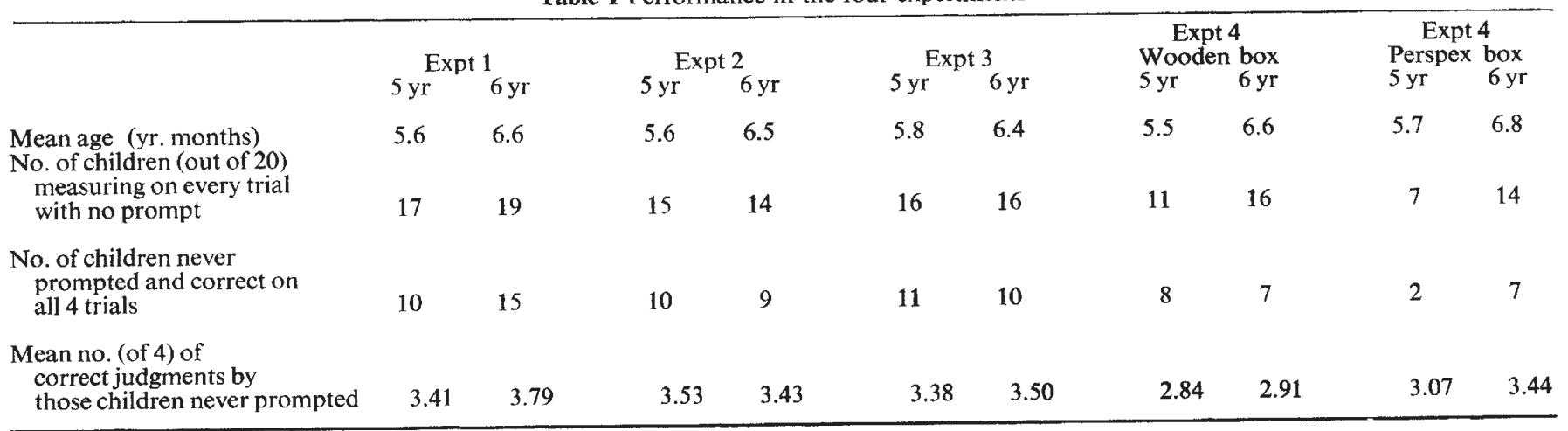

